\title{
Potential unlocked: Art in prison
}

Benedict Carpenter, Nottingham Trent University

Victoria Knight, De Montfort University

This article introduces a three-year project begun in 2018 that investigates the relationship between visual arts education and mental health recovery for prisoners and probationers. The project is delivered in custodial contexts in Leicester, UK. The research engages young offenders with mental health conditions in creating visual artwork for public exhibition and publication. Insight into mental health recovery is gained through semi-structured interviews with participants. Participant well-being is coded through the CHIME framework. Some early findings are that the workshops help to alleviate the deep boredom of prison life; they are a useful distraction and an opportunity for introspection; they promote future thinking; and they help prisoners to connect with families. The research is aligned with the UN Sustainable Development Goal 3: Good health and wellbeing; and Goal 16: Promote peaceful and inclusive societies for sustainable development.

\section{Keywords}

visual art

art education

prison art

mental health

well-being 
recovery

\section{Introduction}

This short statement concerns Potential Unlocked, a three-year Arts Council-funded research project led by the authors. The project investigates the impact of visual arts workshops on young offenders in Leicestershire.

'Potential Unlocked' is an interdisciplinary collaborative project that touches on the intersections between a number of research areas, including arts practice, prison studies, mental health and criminology. It is a collaboration between Soft Touch Arts, Leicester NHS Mental Health Partnership and De Montfort University. The arts workshops are made possible by substantial funding from the Arts Council.

\section{The UN Sustainable Development Goals}

The project is aligned with United Nation's (UN) Sustainable Development Goal 3: Good health and wellbeing, and in particular the UN's targets against this goal to reduce suicide mortality, to strengthen the prevention and treatment of substance abuse, including narcotic drug abuse and harmful use of alcohol, and to improve coverage of treatment interventions (pharmacological, psychosocial and rehabilitation and aftercare services) for substance use disorders (United Nations 2018a).

It is also aligned with goal 16: Promote peaceful and inclusive societies for sustainable development, provide access to justice for all and build effective, accountable and inclusive institutions at all levels (United Nations 2018b). 


\section{The project}

'Potential Unlocked' is a three-year programme to engage young offenders with mental health conditions in creating artwork for public exhibition and publication. These workshops aim to improve the participants' life outcomes through using the arts to open up positive narratives and pathways to recovery and demonstrate a model of good practice for other organizations.

The project was developed out of Soft Touch's work, and the charity's directors should be recognized for their tenacity and focus over the last 30 years. Since 1986, this charity has used arts, media and music activities to help disadvantaged young people to make positive life changes, supporting them to develop creative, social and employability skills. The charity's projects help young people to get back on track when things have gone wrong, to build confidence and resilience to change negative or risky behaviours, and progress to lead more fulfilling lives.

Over the last few years, the charity has worked with young offenders, at Her Majesty's Prison (HMP) Leicester, HMP Stocken and Young Offender Institute (YOI) Glen Parva, putting on visual arts workshops in custodial contexts.

**Figure 1 - should go here**

Figure 1: Flier for Unlocked: An Exhibition of Prison Art from HMP Leicester and Beyond, Soft Touch Arts, 2018.

The authors became involved in the project when the charity approached De Montfort University for help with developing an annual prison art event. The first of these has 
already happened, in September of this year (see Figure 1), and was split between New Walk Museum and Soft Touch's exhibition space - the show gained some attention both in the local and in the national press (for instance BBC News 2018; Anon. 2018), and great feedback from visitors (over 400 feedback cards were returned during the course of the show).

\section{The arts and well-being}

It is reasonably established that arts practice has therapeutic outcomes - indeed, the government is increasingly recognizing this. On 6 November 2018, the Health and Social Care Secretary Matt Hancock announced a major shift towards social prescription - that is health professionals making referrals to arts participation to improve patients' health and well-being (2018). This shift develops the findings of the Creative Health report by the All Party Parliamentary Group on Arts, Health and Wellbeing, which found that (2017):

- the arts and social activities can help keep us well, aid our recovery and support longer lives better lived

- the arts and social activities can help meet major challenges facing health and social care - ageing, loneliness, mental health and other long-term conditions.

However, despite this shift, and the faith that is placed in the arts as a place for developing well-being, we know very little about how this process actually works. Also we know even less about its role in custodial contexts, with all of the particular challenges that prison brings to undertaking arts practice. 
There is some precedent for arts projects in prisons: prison art is annually celebrated in schemes such as the Koestler Awards, a long-standing award that recognizes prison artists' and provides feedback on their work. But here in Leicester, through this project, we have an opportunity to explore, in depth and over a significant period of time, the link between arts practice and well-being. This evidence has the potential to shape the future development of arts interventions.

\section{Prison life}

Prisons are not very nice places and the experience of imprisonment is both disruptive and harmful to not only the prisoner but their families also. Prisons, in our society, are an accepted and established mechanism for delivering punishment for crimes and yet prison numbers continue to rise. Does prison therefore work?

The people who end up in prison are typically vulnerable, presenting with deep mental health problems. They are victims of abusive relationships, drug and alcohol addicts, homeless and have often been raised through the care system. Interventions to help people rebuild their lives are very limited and when projects like this turn up we have to ask how might this help counter the pains of incarceration, and give hope and a sense of an alternative future for inmates. The prison environment is challenging and delivering arts practice in this setting is not easy.

\section{Our method}

As we have mentioned, we are engaged in researching the impact of these visual arts workshops, and developing insight into how and how effectively they work. Our 
method is to use semi-structured interviews, which are transcribed and coded, and then subjected to directed content analysis.

So far we have interviewed key stakeholders about their perceptions of the project and the workshops, and a number of participants in HMP Leicester and offenders on probation with the Community Rehabilitation Company. This will continue and we aim to revisit interview with participants (prisoners and staff) as they progress through the project.

\section{Exploring well-being}

The framework that we find the most useful to explore well-being is the CHIME model.

Perceptions of mental health recovery are, of course, subjective. But in recent years a recovery-based model for mental health has been developed, with research in this area being led by Dr Mary Leamy of King's College London. In 2011, she was one of a number of authors who wrote the influential article: 'Conceptual framework for personal recovery in mental health: systematic review and narrative synthesis' in the British Journal of Psychiatry. This article synthesized published descriptions and models of personal mental health recovery into an empirically based conceptual framework for use in recovery-orientated research and practice.

The result of this synthesis was the identification of five recovery themes comprising:

\section{(C) Connectedness}


(H) Hope and optimism about the future

(I) Identity

(M) Meaning in life

(E) Empowerment

As people recover from poor mental health, these five areas of recovery move through from: pre-contemplation, being a state of ill-health, through active contemplation, preparation, action, and maintenance, growth and good health.

A simple arts activity, such as drawing, provides a space for contemplation and the preparation and action in dealing with negative problems, leading to the forging of new habits and relationships to maintain better health in the future.

This framework has since been adopted by NHS Trusts throughout the United Kingdom, including Leicester NHS Trust.

\section{Early findings}

Some early findings from our research are that:

- The workshops are a highlight for prisoners, helping to alleviate the deep boredom that comes with prison life

- They are a useful distraction and an opportunity for introspection

- The prisoners achieve praise for something that they have produced

- They are an opportunity to think about release, promoting future thinking

- They help prisoners to connect with families. 


\section{Conclusion}

The entire findings will be delivered by 2021 in the form of an academic paper, with interim findings being published on an annual basis.

We would like to run a symposium in the near future to connect colleagues regionally who are working on similar projects, and also to network nationally with colleagues in other universities.

We would also be interested in learning from other colleagues about projects that are aligned with the same UN goals, and in other opportunities to present this research to a wider audience.

\section{References}

All Party Parliamentary Group on Arts, Health and Wellbeing (2017), 'Creative health: The arts for health and wellbeing', National Alliance for Arts Health and Wellbeing (undated), https://www.artshealthandwellbeing.org.uk/appginquiry/Publications/Creative_Health_Inquiry_Report_2017_-_Second_Edition.pdf. Accessed 17 December 2018.

Anon. (2018), 'Unlocked: An exhibition of drawings by prisoners', The Independent, 19 September, https://www.independent.co.uk/arts-entertainment/unlockedexhibition-leicester-prisoner-drawings-art-artwork-a8544541.html. Accessed 21 February 2019. 
BBC News (2018) 'Prisoners create artwork to help with mental health', 15

September, BBC News (2018), https://www.bbc.co.uk/news/uk-england-

leicestershire-45533490. Accessed 21 February 2019.

Hancock, M. (2018), 'The power of the arts and social activities to improve the nation's health', GOV.UK (undated), https://www.gov.uk/government/speeches/thepower-of-the-arts-and-social-activities-to-improve-the-nations-health. Accessed 17 December 2018.

Leamy, M., Bird, V., Le Boutillier, C., Williams, J., Slade, M. (2011), 'Conceptual framework for personal recovery in mental health: Systematic review and narrative synthesis', The British Journal of Psychiatry, 2011:199, pp. 445-52.

United Nations (2018a), 'Sustainable Development Goal 3', Sustainable Development Goals Knowledge Platform (undated), https://sustainabledevelopment.un.org/sdg3. Accessed 17 December 2018.

(2018b), 'Sustainable Development Goal 16', Sustainable Development Goals

Knowledge Platform (undated), https://sustainabledevelopment.un.org/sdg16.

Accessed 17 December 2018.

\section{Contributor details}

Dr Benedict Carpenter is principal lecturer in fine art at Nottingham Trent University. He is an artist, and has taught in art schools and universities since 1998. His research focuses on meaning in the visual arts. This is pursued in two related contexts. The 
first of these is the emergence of meaning through making in art and craft practice. The second is applied research in arts and well-being, and how arts practice creates meaning and narrative for its participants.

Dr Victoria Knight is a prison sociologist working as a senior research fellow at De Montfort University. She has written a book based on her doctoral study exploring the role of in-cell television in prisons. More recently her work has become directed at the use of digital technology in prisons. She has spent many years researching inside our prisons and is ever curious of life inside.

Contact:

Benedict Carpenter, Nottingham Trent University

50 Shakespeare Street, Nottingham. NG1 4FQ

E-mail: benedict.carpenter@ntu.ac.uk

https://orcid.org/0000-0001-5014-1328

Victoria Knight, De Montfort University

Gateway House, Leicester LE1 9BH

E-mail: vknight@dmu.ac.uk 